\title{
The Potential Role of Quercus infectoria Gall Extract on Osteoblast Function and Bone Metabolism
}

\author{
Hermizi Hapidin ${ }^{1}$, Hasmah Abdullah ${ }^{1}$, Ima Nirwana Soelaiman ${ }^{2}$ \\ ${ }^{1}$ Biomedicine Programme, School of Health Sciences, Universiti Sains Malaysia, Penang, Malaysia \\ ${ }^{2}$ Department of Pharmacology, UKM Medical Centre, Universiti Kebangsaan Malaysia, Bangi, Malaysia \\ Email: hermizi@kck.usm.my
}

Received September 7, 2012; revised October 8, 2012; accepted November 9, 2012

\begin{abstract}
The galls of the Quercus infectoria (QI) tree are traditionally believed to have great medicinal value. Pharmacologically the galls are claimed to have various biological activities such as astringent effect, antidiabetic, antitremorine, local anaesthetic, antipyretic, anti-inflammatory, antibacterial, antiviral and many more. These pharmacological activities of gall extracts were reported to be due to its excellent antioxidant activity with phytochemicals constituents of phenolic and flavanoid compounds. The phenolic compounds or polyphenols can act on bone metabolism by modulating osteoblast proliferation, differentiation and mineralization, as well as osteoclastogenesis. In addition, elemental and physico-chemical analysis indicated the presence of important minerals in QI, such as calcium, magnesium, phosphorus, oxygen, potassium, aluminium, carbon, zinc, iron, manganese, nickel and silica. The current review will be focusing on the potential bone health benefits of the well-known traditional herbal medicine, QI or locally known as the "manjakani”.
\end{abstract}

Keywords: Quercus Infectoria; Osteoblast; Bone Metabolism; Polyphenols

\section{Introduction}

Bone is a unique tissue providing support and mineral balance for the organism. It is formed during growth and is maintained during adult life by continuous renewal of the matrix, a process called bone remodeling. Bone remodeling is ensured by two cell types: osteoclasts, which resorb the calcified bone matrix, and osteoblasts, which are responsible for new bone matrix synthesis. During growth, bone formation exceeds bone resorption, resulting in bone expansion. In the young adult, bone resorption is balanced by bone formation, resulting in maintenance of bone mass. With aging and after the menopause, an imbalance in bone resorption relative to formation results in a negative bone balance at the tissue level. This may lead to osteoporosis, a common skeletal disease characterized by reduced bone mass, deterioration of bone microarchitecture, and increased susceptibility to fractures $[1,2]$.

Osteoporosis is now widely recognized as a public health problem since this disease is associated with significant mortality and morbidity as well as heavy medical expenses throughout the world. The current consensus is that approximately 1.66 million hip fractures occur each year worldwide. The incidence is set to increase 4-fold by the year 2050 because of the increasing numbers of older people and the age-adjusted incidence rates are many times higher in Western countries than in Asia and sub-Saharan African [3-5]. Although osteoporosis is widely regarded as a disease that affects women, it had also become a major problem for older men. Eastell et al. reported that $20 \%$ of symptomatic spine fractures and 30\% of hip fractures in countries with high fracture rates occurred in men [6].

Osteoporosis is associated with huge personal and economic tolls. In Europe, the disability due to osteoporosis was greater than that caused by cancers (with the exception of lung cancer) and the resulting disability was comparable to or greater than the disability due to a variety of chronic non-communicable diseases, such as rheumatoid arthritis, asthma and high blood pressure-related heart disease [7]. In Malaysia and Thailand, hip fracture rates of between 200 to 250 fractures per 100,000 were found [8]. Healthy urban midlife Malaysian women had a $24 \%$ prevalence of osteoporosis and $51.6 \%$ of osteopenia, predominantly at the hip [9].

Various pharmacological agents for managing osteoporosis are available, for example hormone replacement therapy, bisphosphonates, calcium, calcitonin, androgens, parathormone and growth hormone. Conventional treatment results in varied adverse effects such as increased incidence of endometrial and breast cancer with hormonal replacement therapy, pseudo-arthritis with fluo- 
ride treatment, extra skeletal effects in cases treated with growth factors such as insulin like growth factor I and II and transforming growth factor $[10,11]$. Considering the broad range of effects of osteoporosis on the medical and health system, currently there is an increasing demand for alternative medications that can prevent and cure this silent ailment [12]. In this paper, we have reviewed the literature related to a selected medicinal herb, Quercus infectoria which may act specifically on osteoblastic proliferation and differentiation.

\section{Quercus infectoria}

Quercus infectoria (QI) or manjakani is a small oak tree indigenous to Asia Minor and Persia. It is found in the Kumaun, Garhwal and Bijnor forests in India [13]. Although QI is not an indigenous to Malaysia, it is commonly utilized among the local Malay women as a herb especially for postpartum care [14]. QI or majuphal as it is known in India, is considered as one of the most powerful vegetable astringents in Indian medicine. It is used in the form of powder, decoction, infusion and ointment. Previous studies stated that QI had been used as a dental powder in the treatment of toothache and gingivitis $[13,15,16]$. However, the mechanism of the effects of QI on tooth and gingiva were not elucidated.

The oak galls, used in commerce and medicine, are excrescences of the QI tree. It is formed as a result of the puncture of the bark of young twigs by the female gall-wasp, Cynips Gallae-tinctoriae, which lays its eggs inside. The young larva that hatches from the eggs feeds upon the tissues of the oak and secretes a peculiar fluid in its mouth. This fluid stimulates the cells of the tissues to rapidly divide resulting in abnormal development and the formation of a gall. The larva becomes completely enclosed in a nearly spherical mass, which projects from the twig, furnishing it with a supply of starch and other nutritive material. The growth of the gall continues as the egg or larva lives and reaches maturity. It then changes into a chrysalis, from which the fully develop gall-wasp will emerge and escape into the air through a hole bored with its mandibles at the side of the gall. For medicinal use, galls are collected before the insect escapes [13].

Elemental and physico-chemical analyses indicated the presence of important minerals in QI, such as calcium (Ca), magnesium (Mg), phosphorus $(\mathrm{P})$, oxygen $\left(\mathrm{O}_{2}\right)$, potassium $(\mathrm{K})$, aluminium $(\mathrm{AI})$, carbon $(\mathrm{C})$, zinc $(\mathrm{Zn})$, iron (Fe), manganese (Mn), nickel (Ni) and silica (Si) [17,18] (Table 1). Thus, QI may be a good source of minerals to treat a number of diseases that are mainly due to the deficiency of those minerals, for example osteoporosis which is a condition caused by Ca deficiency.

Numerous studies have reported the essentiality of Ca and vitamin D for bone health [19-21]. Ca is one of the
Table 1. Elemental composition of QI by using atomic absorption spectrophotometer.

\begin{tabular}{ccc}
\hline No. & Elements (ppm) & Quercus infectoria (in 5\% HCI) \\
\hline 1 & Calcium (Ca) & 12,700 \\
2 & Phosphorus (P) & 11,100 \\
3 & Potassium (K) & 223,633 \\
4 & Magnesium (Mg) & 20,933 \\
5 & Iron (Fe) & 3587 \\
6 & Manganese (Mn) & 100 \\
7 & Zinc (Zn) & 329 \\
8 & Nickel (Ni) & 213 \\
\hline
\end{tabular}

Edited from Vermani et al. 2010 [18].

main bone-forming minerals and an appropriate supply to bone is essential at all stages of life. Studies in populations with a low average intake of calcium suggest an increasing risk of hip fracture with declining calcium intake [22-24]. Both $\mathrm{Ca}$ and $\mathrm{P}$ are required for the appropriate mineralization of the skeleton and a depletion of serum phosphate leads to impaired bone mineralization and compromised osteoblast function [25]. In addition to that, $\mathrm{Mg}$ is involved in bone and mineral homeostasis and is important in bone crystal growth and stabilization [26]. A significant correlation has been observed between serum Mg and bone metabolism. Gur et al. [27] demonstrated lower serum values of $\mathrm{Mg}$ in 70 osteoporotic subjects compared to 30 non-osteoporotic postmenopausal women. Furthermore, Marangella et al. [28] had suggested that treatment with an alkaline salt, such as potassium citrate can reduce bone resorption levels in postmenopausal women with low bone density. Thus, the mineral constituents of QI may provide benefit to bone metabolism and prevent or even reverse osteoporosis.

The QI gall extract is thought to have a variety of pharmacological properties including anti-diabetic [29], anti-tremor [30], local anesthetic, antiviral [31], antibacterial [32], anti-fungal [33], larvicidal [34], antimicrobial [35], anti-inflammation [36], wound healing [37] and many more. Umachigi et al. [38] found noticeable antioxidant activity in the QI gall extract, as the extract inhibited the superoxide and 1,1-diphenyl-2-picrylhydrazyl (DPPH) radical scavenging activities, and tyrosinase activities [39]. Flavonoid and phenolic compounds extracted from the QI galls are believed to have potential antioxidant activity and are often correlated with the antioxidant activity of phytomaterials.

The QI galls possessed potent free radical quenching and potent antioxidant activity when tested both in chemical as well as biological models [40]. The main 
constituents found in the QI galls are tannins (gallotannic acid) $(50 \%-70 \%)$, gallic acid $(2 \%-4 \%)$, ellagic acid, sugar and essential oils [41]. Other phytochemicals such as amentoflavone, hexamethyl ether, iso-cryptomerin and beta-sitosterol have also been isolated from QI [13]. Phytochemicals or phytonutrients are a large group of plant-derived chemical compounds and are divided into several classes: phenolics or polyphenols (flavonoids, phenolic acids, tannins, stilbenes, coumarins and lignans), carotenoids, alkaloids, sterols, terpenes and fibre. Phytochemicals produced by plants are used to protect themselves, but recent research demonstrates that certain molecules may protect humans against some pathologies such as cancer, cardiovascular diseases and osteoporosis [42]. Polyphenols are aromatic compounds. Of all the aromatic compounds, flavonoids and tannins are most commonly found in plant organs [43]. As previously reviewed by Habauzit \& Horcajada [44], polyphenols can act on bone metabolism by modulating osteoblast proliferation, differentiation and mineralization, as well as osteoclast function [45].

\section{The Osteoblast}

Osteoblasts involved in bone formation are derived from precursors originating in the bone marrow. These precursors are multipotent mesenchymal stem cells that can be differentiated into several kinds of tissue specific cells such as osteoblasts, myoblasts, adipocytes and chondrocytes [45]. Bone formation is a tightly regulated process which is characterized by a sequence of events starting with the commitment of osteoprogenitor cells, their differentiation into pre-osteoblasts and finally mature osteoblasts whose function is to synthesize bone matrix that becomes progressively mineralized. Inherently, based on observations in vivo and in bone nodule formation in vitro, the process is subdivided into three stages: 1) proliferation; 2) extracellular matrix development and maturation (differentiation); and 3) mineralization [46]. Each stage is regulated by the coordinated expression of major transcription factors [47].

The most important transcription factors controlling bone formations are RunX2, Osterix, $\beta$-catenin, activating transcription factor-4, activator protein-1 (AP-1) and CCAAT/enhancer binding proteins (C/EBP). Other transcription factors belonging to homeobox proteins (Msx and D1x proteins) or to helix-loop-helix protein (Id and Twist) may play a role in osteoblast development [47]. Furthermore, the expression of all these transcription factors is known to be modulated by several hormones; parathyroid hormone (PTH), oestrogen, glucocorticoids, 1,25-dihydroxyvitamin $\mathrm{D}_{3}\left[1,25(\mathrm{OH})_{2} \mathrm{D}_{3}\right]$, or growth factors; bone morphogenetic protein (BMP), transforming growth factor- $\beta$ (TGF- $\beta$ ), insulin-like growth factor-1 (IGF-1), fibroblast growth factor-2 (FGF-2) [48,49]. For example, PTH promotes bone formation in part through phosphorylation and activation of Runx2, resulting in activation of osteoblast genes [50]. Several research groups, using cell culture systems, have demonstrated that BMPs are potent local factors that regulate osteoblast differentiation [51-54].

Osteoblasts express various phenotypic markers such as alkaline phosphatase (ALP) collagen type 1, osteopontin (OPN), bone sialoprotein (BSP) and osteocalcin (OCN). Many markers are available and are currently used to study the influence of several factors on osteoblast developmental stages or functions. Indeed, ALP, OPN and bone BSP are early markers of the osteoblast phenotype while OCN plays a role in mineralization [55]. In general, ALP increases and then decreases when mineralization is well progressed, OPN peaks twice during proliferation and then again later but prior to certain other matrix proteins, including BSP and OCN. BSP is expressed transiently very early and is then upregulated again in differentiated osteoblasts forming bone and OCN appears approximately concomitantly with mineralization [46].

Research also suggests that osteoblasts exert an influence on osteoclasts by using receptors that can control the chemical or hormonal signals which would either initiate or inhibit osteoclastic action [56]. Osteoclasts are derive from haematopoietic progenitors (monocyte/macrophage lineage) in the bone marrow and are responsible for bone resorption. Osteoblasts can produce both RANK-L (the ligand for receptor activator of nuclear factor-kappa $\beta$, NF- $\kappa \beta$ ) and osteoprotegerin. Indeed, RANK-ligand binds to RANK on osteoclast precursors and stimulates osteoclast proliferation, whereas osteoprotegerin (a circulating binder of RANK-ligand), reduces the amount of RANK-ligand and thus osteoclast activity [57]. These inherent qualities of the osteoblast aid the coupling of osteoblasts to osteoclasts which is vital in bone remodeling process [58,59].

Active osteoblasts are found on the surface of newly formed bone, where they synthesize the organic matrix and regulate mineralization. Once the osteoblast has completed bone formation it can undergo various transformations, either becoming a flattened bone lining cell, undergo programmed cell death (apoptosis), or it can become embedded within the newly formed bone tissue transforming into an osteocyte [60-62].

\section{Effects of Polyphenols on Bone Metabolism}

To the best of our knowledge, the effect of QI gall extract on bone metabolism has never be reported. However, several studies have found that polyphenols can act on human cells. Studies on modulation of cell function by polyphenols had been performed in different 
in vitro models such as cancer cells [63,64], epithelial cells $[65,66]$ or skeletal cells, but little is known regarding osteoblastic cells. The only available data with respect to osteoblasts is from $\mathrm{Bu}$ et al. [67], who studied the influence of dried plum polyphenol extract on MC3T3-E1 on osteoblasts under normal and inflammatory conditions. This extract was found to be non toxic for osteoblasts, and was able to stimulate alkaline phosphatase (ALP) activity and mineralized nodule formation. They concluded that the dried plum polyphenols enhance osteoblast activity and function by up-regulating Runx2, Osterix and IGF-I and increasing lysyl oxidase expression, and at the same time attenuate osteoclastogenesis signaling [67].

Moreover, a short-term clinical study with postmenopausal women demonstrated that dietary supplementation with $100 \mathrm{~g}$ of dried plums (a rich source of phenolic and flavonoid compounds) per day for 3 months positively influenced the bone formation markers, bone-specific alkaline phosphatase (BSAP) and IGF-1. Higher levels of both serum IGF-I and BSAP are associated with greater rates of bone formation by osteoblasts [68].

Gallotannins, which are parts of polyphenols, have been shown to regulate multiple biological activities including antioxidative and antitumor capacities. However, their effects on bone metabolism remain to be elucidated [44]. The only study available had been carried out by Park et al. [69]. They found that furosin, an elagitannin has an inhibitory activity on the differentiation of both murine bone marrow mononuclear cells and Raw264.7 cells into mature osteoclasts. Park et al. [69] conclude that furosin could modulate osteoclastic function through mechanisms involving inhibition of RANKL-induced p38MAPK and JNK/AP-1 activation as well as by actin ring formation.

Recently, Holzer et al. (2012) [70], showed that green tea extract (GTE) with high levels of polyphenols (mainly catechins) may influence bone mineral density (BMD) in smokers by reducing their oxidative stress levels and enhancing viability of osteoblasts, thus on doing so, supporting bone healing in general. They conclude that dietary supplementation with GTE appears to be an effective and simple way to counter high reactive oxygen species (ROS) level due to cigarette smoke. In addition to that, supplementation with green tea polyphenols (GTF) in female rats resulted in higher values of bone formation indicators [femoral bone mineral content (BMC), BMD and serum OCN], but lower the values of bone resoprtion indicators [serum tartrate-resistant acid phosphate (TRAP), urinary 8hydroxy-2'-deoxyguanosine (8-OHdG) and cyclooxygenase-2 (COX-2) levels] [71].

All of the previous findings indicate that polyphenols may give effects not only on osteoblasts but also on os- teoclasts. Polyphenols can enhance osteoblast activity and mineralization by up-regulating Runx2, Osterix, IGF-I, BSAP, ALP, OCN, BMC, BMD as well as inhibit osteoclastogenesis via inhibition of RANKL expression, TRAP, 8-OHdG, COX-2 levels, and activation of JNK/ AP-1. These combined effects of polyphenols on osteoblasts and osteoclasts are useful in maintaining the bone remodeling process which is the key endpoint in the management of osteoporosis [45].

\section{Conclusion}

Osteoporosis is considered as a worldwide major public health problem. To overcome the wide range of side effects produced by the synthetic osteoporotic drugs, it is desirable to find a new naturally occuring anabolic agent or the so-called "green medicine" that can stimulate new bone formation, which is primarily a function of the osteoblasts. The QI gall extract contains high levels of important minerals (calcium, phosphorus, potassium and magnesium) and polyphenols which are important for long-term bone health and for the prevention of osteoporosis. Although evidence of a link between polyphenols and osteoblasts is not sufficiently strong to give precise dietary recommendations, the related accumulating data suggests that QI may have a potential anabolic effect on bone metabolism. Therefore, laboratory studies need to be done to answer the question of whether QI can produce an effect on bone metabolism (especially on the osteoblasts) and eventually elucidate the exact mechanism of the action of QI on bone which can lead to fundamental knowledge that may be used to derive a new source for the treatment of osteoporosis.

\section{Acknowledgements}

The authors were grateful to the Universiti Sains Malaysia for funding this work under USM short term grant number 304/PPSK/61312042.

\section{REFERENCES}

[1] L. G. Raisz, "Pathogenesis of Osteoporosis: Concepts, Conflicts, and Prospects," Journal of Clinical Investigation, Vol. 115, No. 12, 2005, pp. 3318-3325. doi:10.1172/JCI27071

[2] M. P. Caulfield and R. E. Reitz, "Biochemical Markers of Bone Turnover and Their Utility in Osteoporosis,” Medical Laboratory Observer (MLO), Vol. 36, No. 4, 2004, pp. 34-37.

[3] “Fractures Neck of Femur,” Royale Collage of Physicians, London, 1989.

[4] C. Cooper, G. Campion and L. J. Melton, "Hip Fractures in the Elderly: A World-Wide Projection,” Osteoporosis International, Vol. 2, No. 6, 1992, pp. 285-289. doi:10.1007/BF01623184 
[5] L. J. Melton, “Epidemiology of Fractures,” In: L. J. Melton, Ed., Osteoporosis: Etiology, Diagnosis, and Management, Lippincott-Raven, Philadelphia, 1995, pp. 225247.

[6] R. Eastell, I. T. Boyle, J. Compston, et al., "Management of Male Osteoporosis: Report of the UK Consensus Group," Quarterly Journal of Medicine, Vol. 91, No. 2, 1998, pp. 71-92. doi:10.1093/qjmed/91.2.71

[7] O. Johnell and J. A. Kanis, "An Estimate of the Worldwide Prevalence and Disability Associated with Osteoporotic Fractures,” Osteoporosis International, Vol. 17, No. 12, 2006, pp. 1726-1733. doi:10.1007/s00198-006-0172-4

[8] E. Lau, P. Suriyamongpaisal, J. Lee, et al., "Risk Factors for Hip Fracture in Asian Men and Women: The Asian Osteoporosis Study," Journal of Bone and Mineral Research, Vol. 16, No. 3, 2001, pp. 572-580. doi:10.1359/jbmr.2001.16.3.572

[9] P. S. Lim, F. B. Ong, N. Adeeb, et al., "Bone Health in Urban Midlife Malaysian Women: Risk Factors and Prevention," Osteoporosis International, Vol. 16, No. 12, 2005, pp. 2069-2079. doi:10.1007/s00198-005-2003-4

[10] S. R. Joshi and D. V. Paramar, “Osteoporosis," The Indian Practice, Vol. 50, 1997, pp. 254-268.

[11] M. Wheeler, "Osteoporosis,” Medical Clinics of North America, Vol. 60, No. 6, 1976, pp. 1213-1224.

[12] S. K. Mitra, M. V. Venkataranganna, S. Gopumadhava, et al., "The Beneficial Effect of OST-6 (OsteoCare, a Herbomineral Formulation in Experimental Osteoporosis," Phytomedicine, Vol. 8, No. 3, 2001, pp. 195-201. doi:10.1078/0944-7113-00034

[13] C. P. Khare, “Quercus," Indian Herbal Remedies: Rational Western Therapy, Ayurvedic and Other Traditional Usage, 2004, pp. 395-396.

[14] Z. Muhammad and A. M. Mustafa, "Traditional Malay Medicine Plants,” Penerbit Fajar Bakti Sdn. Bhd, Kuala Lumpur, 1994.

[15] A. V. S. Kottakkal, "Indian Medicinal Plants," Orient Longman Ltd., Andhra Pradesh, 1995.

[16] S. K. Bhattacharjee, "Handbook of Medicinal Plants," Pointer Publishers, Jaipur, 2001.

[17] L. K. Soon, E. Hasni, K. S. Law, et al., "Ultrastructural Findings and Elemental Analysis of Quercus Infectoria Oliv,” Annals of Microscopy, Vol. 7, 2007, pp. 32-37.

[18] A. Vermani, Navneet, Prabhat and A. Chauhan, "PhysicoChemical Analysis of Ash of Some Medicinal Plants Growing in Uttarakhand, India," Nature and Science, Vol. 8, No. 6, 2010, pp. 88-91.

[19] S. A. New, "Bone Health: The Role of Micronutrients," British Medical Bulletin, Vol. 55, No. 3, 1999, pp. 619633. doi:10.1258/0007142991902501

[20] J. Z. Ilich and J. E. Kerstetter, "Nutrition in Bone Health Revisited: A Story Beyond Calcium," Journal of the American Collage of Nutrition, Vol. 19, No. 6, 2000, pp. 715-737.

[21] R. P. Heaney, "Bone Health,” The American Journal of Clinical Nutrition, Vol. 85, 2007, pp. 300S-303S.
[22] E. Lau, S. Donnan, D. J. Barker and C. Cooper, "Physical Activity and Calcium Intake in Fracture of the Proximal Femur in Hong Kong,” British Medical Journal, Vol. 297, No. 6661, 1988, pp. 1441-1443. doi:10.1136/bmj.297.6661.1441

[23] O. Johnell, B. Gullberg, J. A. Kanis, et al., "Risk Factors for Hip Fracture in European Women: The MEDOS Study,” Journal of Bone and Mineral Research, Vol. 10, No. 11, 1995, pp. 1802-1815. doi:10.1002/jbmr.5650101125

[24] J. Kanis, O. Johnell, B. Gullaberg, et al., "Risk Factors of Hip Fracture in Men from Southern Europe: The MEDOS Study. Mediterranean Osteoporosis Study," Osteoporosis International, Vol. 9, No. 1, 1999, pp. 45-54. doi:10.1007/s001980050115

[25] “American Society for Bone and Mineral Research," In: M. Favus, Ed., Primer of the Metabolic Bone Diseases and Disorders of Mineral Metabolism, Lippincott Williams \& Wilkins, Philadelphia, 1999, pp. 257-284.

[26] A. Prentice, "Diet, Nutrition and the Prevention of Osteoporosis," Public Health Nutrition, Vol. 7, No. 1A, 2004, pp. 227-243. doi:10.1079/PHN2003590

[27] A. Gur, L. Colpan, K. Nas, R. Cevik, et al., "The Role of Trace Minerals in the Pathogenesis of Postmenopausal Osteoporosis and a New Effect of Calcitonin,” Journal of Bone and Mineral Metabolism, Vol. 20, No. 1, 2002, pp. 39-43. doi:10.1007/s774-002-8445-y

[28] M. Marangella, M. D. Stefano, S. Casalis, S. Berutti, et al., "Effects of Potassium Citrate Supplementation on Bone Metabolism," Calcified Tissue International, Vol. 74, No. 4, 2004, pp. 330-335. doi:10.1007/s00223-003-0091-8

[29] J. K. Hwang, T. W. Kong, N. I. Baek and Y. R. Pyun, " $\alpha$-Glycosidase Inhibitory Activity of Hexagalloyl Glucose from the Galls of Quercus Infectoria," Planta Medica, Vol. 66, No. 3, 2000, pp. 273-274. doi:10.1055/s-2000-8569

[30] M. S. Dar, M. Ikram and T. Fakouhi, "Pharmacology of Quercus infectoria oliv," Journal of Pharmaceutical Sciences, Vol. 46, No. 6, 1976, pp. 1791-1794. doi:10.1002/jps.2600651224

[31] G. Hussein, H. Miyashiro, N. Nakamura, M. Hattori, et al., "Inhibitory Effects of Sudanese Medicinal Plant Extracts on Hepatitis C Virus Protease," Phytotherapy Research, Vol. 14, No. 7, 2000, pp. 510-516. doi:10.1002/1099-1573(200011)14:7<510::AID-PTR646 $>3.0 . \mathrm{CO} ; 2-\mathrm{B}$

[32] S. Fatima, A. H. A. Farooqi, R. Kumar, T. R. S. Kumar TRS and S. P. S. Khanuja, "Antibacterial Activity Possessed by Medicinal Plants Used in Tooth Powders," Journal of Medicinal and Aromatic Plant Sciences, Vol. 22, No. 4a, 2001, pp. 187-189.

[33] M. Digraki, M. H. Alma, A. Ilcim and S. Sen, "Antibacterial and Antifungal Effects of Various Commercial Plant Extracts,” Pharmaceutical Biology, Vol. 37, No. 3, 1999, pp. 216-220. doi:10.1076/phbi.37.3.216.6307

[34] A. Redwane, H. B. Lazrek, S. Bouallam, M. Markouk, et al., "Larvicidal Activity of Extracts from Quercus lusitania var. infectoria Galls (Oliv.)," Journal of Ethnophar- 
macology, Vol. 79, No. 2, 2002, pp. 261-263. doi:10.1016/S0378-8741(01)00390-7

[35] S. Voravuthikunchai, A. Lortheeanuwat, W. Jeeju, T. Sririrak, et al., "Effective Medicinal Plants against Enterohaemorrhagic Escherichia coli O 157:H7,” Journal of Ethnopharmacology, Vol. 94, No. 1, 2004, pp. 49-50. doi:10.1016/j.jep.2004.03.036

[36] G. Kaur, H. Hamidi, A. Ali, M. S. Alam and M. Athar, "Anti-Inflammatory Evaluation of Alcoholic Extract of Galls of Quercus infectoria," Journal of Ethnopharmacology, Vol. 90, No. 2-3, 2004, pp. 285-292. doi:10.1016/j.jep.2003.10.009

[37] S. P. Umachigi, K. N. Jayaveera, C. K. Ashok Kumar, et al., "Studied on Wound Healing Properties of Quercus infectoria," Tropical Journal of Pharmaceutical Research, Vol. 7, No. 1, 2008, pp. 913-919.

[38] S. P. Umachigi, K. N. Jayaveera, C. K. Ashok Kumar and G. S. Kumar, "Antioxidant Potential of Galls of Quercus infectoria," The Internet Journal of Pharmacology, Vol. 5, No. 2, 2008.

[39] S. Rohana, S. Vimala, A. Abdul Rashih and A. Mohd IIham, "Skin Whitening and Antioxidant Properties of Quercus infectoria Galls," Proceedings of the Seminar on Medicinal Plant, Forest Research Institute Malaysia (FRIM), Selangor, 20-21 July 2004, pp. 188-191.

[40] G. Kaur, M. Athar and M. S. Alam, "Quercus infectoria Galls Possess Antioxidant Activity and Abrogates Oxidative Stress-Induced Functional Alterations in Murine Macrophages," Chemico-Biological Interactions, Vol. 171, No. 3, 2008, pp. 272-282. doi:10.1016/j.cbi.2007.10.002

[41] J. Bruneton, "Pharmacognosy: Phyochemistry, Medicinal Plants,” 2nd Edition, Lavoisier Publication, Hampshire, 1999.

[42] A. Scalbert, C. Manach, C. Morand, et al., "Dietary Polyphenols and the Prevention of Diseases," Critical Review in Food Science and Nutrition, Vol. 45, No. 4, 2005, pp. 287-306. doi:10.1080/1040869059096

[43] Z. Luthar, "Polyphenol Classification and Tannin Content of Buckwheat Seeds (Fagopyrum esculentum Moench)," Fagopyrum, Vol. 12, 1992, pp. 36-42.

[44] V. Habauzit and M. N. Horcajada, "Phenolic Phytochemicals and Bone," Phytochemistry Reviews, Vol. 7, No. 2, 2008, pp. 313-344.

[45] A. Trzeciakiewicz, V. Habauzit and M. N. Hocajada, "When Nutrition Interacts with Osteoblast Function: Molecular Mechanisms of Polyphenols," Nutrition Research Reviews, Vol. 22, No. 1, 2009, pp. 68-81. doi:10.1017/S095442240926402X

[46] J. E. Aubin, "Mesenchymal Stem Cells and Osteoblast Differentiation,” In: J. P. Bilezikian, L. G. Raisz and T. J. Martin, Eds., Principals of Bone Biology, Academic Press, San Diego, 2008, pp. 85-107. doi:10.1016/B978-0-12-373884-4.00026-4

[47] P. J. Marie, "Transcription Factors Controlling Osteoblastogenesis," Archives of Biochemistry and Biophysics, Vol. 473, No. 2, 2008, pp. 98-105. doi:10.1016/j.abb.2008.02.030
[48] G. J. Strewler, "Local and Systemic Control of the Osteoblast,” Journal of Clinical Investigation, Vol. 107, No. 3, 2001, pp. 271-272. doi:10.1172/JCI11777

[49] D. J. Baylink, R. D. Finkelman and S. Mohan, "Growth Factors to Stimulate Bone Formation," Journal of Bone and Mineral Research, Vol. 8, No. S2, 1993, pp. S565S572. doi:10.1002/jbmr.5650081326

[50] V. Krishnan, T. L. Moore, Y. L. Ma, L. M. Helvering, et al., "Parathyroid Hormone Bone Anabolic Action Requires Cbfa1/Runx2-Dependent Signaling," Molecular Endocrinology, Vol. 17, No. 3, 2003, pp. 423-435. doi:10.1210/me.2002-0225

[51] T. Katagiri, Yamaguchi, A. Ikeda, T. Yoshiki, et al., "The Non-Osteogenic Mouse Pluripotent Cell Line, C3H10T1/2, Is Induced to Differentiate into Osteoblastic Cells by Recombinant Human Bone Morphogenetic Protein-2,” Biochemical and Biophysical Research Communications, Vol. 172, No. 1, 1990, pp. 295-299. doi:10.1016/S0006-291X(05)80208-6

[52] A. Yamaguchi, T. Katagiri, T. Ikeda, J. M. Wozney, et al., "Recombinant Human Bone Morphogenetic Protein-2 Stimulates Osteoblastic Maturation and Inhibits and Inhibits Myogenic Differentiation in Vitro," The Journal of Cell Biology, Vol. 113, No. 3, 1991, pp. 681-687. doi:10.1083/jcb.113.3.681

[53] T. K. Sampath, J. C. Maliakal, P. V. Hauschka, W. K. Jones, et al., "Recombinant Human Osteogenic Protein-1 (hOP-1) Induces New Bone Formation in Vitro with a Specific Activity Comparable with Natural Bovine Osteogenic Protein and Stimulates Osteoblast Proliferation and Differentiation in Vitro," The Journal of Biological Chemistry, Vol. 267, No. 28, 1992, pp. 20352-20362.

[54] S. E. Gitelman, M. Kirk, E. H. Filvaroff, A. J. Kahn, et al., "Vgr-1/BMP-6 Induces Osteoblastic Differentiation of Pluripotential Mesenchymal Cells," Cell Growth and Differentiation, Vol. 6, No. 7, 1995, pp. 827-836.

[55] G. S. Stein and J. B. Lian, "Molecular Mechanisms Mediating Proliferation Differentiation Interrelationships during Progressive Developmental of the Osteoblast Phenotype," Endocrine Reviews, Vol. 14, No. 4, 1993, pp. 424-442.

[56] S. Marks and P. Odgren, "Structure and Developmental of the Skeleton,” In: J. P. Bilezikian, L. G. Raisz and G. A. Rodan, Eds., Principles of Bone Biology, Academic Press, San Diego, 2002, pp. 3-15.

[57] L. C. Hofbauer and A. E. Heufelder, "Role of Receptor Activator of Nuclear Factor Kappa-B Ligand and Osteoprotegerin in Bone Cell Biology," Journal of Molecular Medicine, Vol. 79, No. 5-6, 2001, pp. 243-253. doi:10.1007/s001090100226

[58] J. Lian, G. Stein, E. Canalis, P. Gehron Robey and A. Boskey, "Bone Formation: Osteoblast Lineage Cells, Growth Factors, Matrix Proteins and the Mineralization Process,” In: M. Favus, Ed., Primer on Metabolic Diseases and Disorders of Mineral Metabolism, Lippincott William \& Wilkins, Philadelphia, 1999, pp. 14-29.

[59] A. M. Parfitt, "The Mechanism of Coupling: A Role for the Vasculature,” Bone, Vol. 26, No. 4, 2000, pp. 319-323. doi:10.1016/S8756-3282(00)80937-0 
[60] A. M. Parfitt, “Osteonal and Hemi-Osteonal Remodeling: The Spatial and Temporal Framework for Signal Traffic in Adult Human Bone,” Journal of Cellular Biochemistry, Vol. 55, No. 3, 1994, pp. 273-286. doi:10.1002/jcb.240550303

[61] R. Baron, “Anatomy and Ultrastructural of Bone,” In: M. Favus, Ed., Primer on the Metabolic Bone Diseases and Disorders of Mineral Metabolism, Lippincott William \& Wilkins, Philadelphia, 1999, pp. 3-10.

[62] D. Sommerfeldt and C. Rubin, "Biology of Bone and How It Orchestrates the Form and Function of the Skeleton,” European Spine Journal, Vol. 10, No. S2, 2001, pp. S86-S95. doi:10.1007/s005860100283

[63] V. Noe, S. Penuelas, R. M. Lamuela-Raventos, et al., "Epicatechin and a Cocoa Polyphenolic Extract Modulate Gene Expression in Human Caco-2 Cells,” Journal of Nutrition, Vol. 134, No. 10, 2004, pp. 2509-2516.

[64] C. H. Ko, S. C. Shen, H. Y. Lin, et al., "Flavanones Structure-Related Inhibition on TPA-Induced Tumor Promotion through Suppression of Extracellular Signal-Regulated Protein Kinases: Involvement of Prostaglandin E-2 in Anti-Promotive Process,” Journal of Cellular Physiology, Vol. 193, No. 1, 2002, pp. 93-102. doi:10.1002/jcp.10154

[65] J. O’Prey, J. Brown, J. Fleming, et al., "Effects of Dietary Flavonoids on Major Signal Transduction Pathways in Human Epithelial Cells," Biochemical Pharmacology, Vol. 66, No. 11, 2003, pp. 2075-2088. doi:10.1016/j.bcp.2003.07.007

[66] R. Vittal, Z. E. Selvanayagam, Y. Sun, et al., "Gene Expression Changes Induced by Green Tea Polyphenol (2)Epigallocatechin-3-Gallate in Human Bronchial Epithelial
21BES Cells Analyzed by DNA Microarray,” Molecular Cancer Therapeutics, Vol. 3, No. 9, 2004, pp. 1091-1099.

[67] S. Y. Bu, T. S. Hunt and B. J. Smith, "Dried Plum Polyphenols Attenuate the Detrimental Effects of TNF-a on Osteoblast Function Coincident with Up-Regulation of Runx2, Osterix and IGF-I," The Journal of Nutritional Biochemistry, Vol. 20, No. 1, 2009, pp. 35-44. doi:10.1016/j.jnutbio.2007.11.012

[68] B. H. Arjmandi, D. A. Khalil, E. A. Lucas, et al., "Dried Plumps Improve Indices of Bone Formation in Postmenopausal Women,” Journal of Women's Health Gender-Based Medicine, Vol. 11, No. 1, 2002, pp. 61-68. doi:10.1089/152460902753473471

[69] E. K. Park, M. S. Kim, S. H. Lee, et al., "Furosin, an Ellagitannin, Suppresses RANKL-Induced Osteoclast Differentiation and Function through Inhibition of MAP Kinase Activation and Actin Ring Formation," Biochemical and Biophysical Research Communications, Vol. 325, No. 4, 2004, pp. 1472-1480. doi:10.1016/j.bbrc.2004.10.197

[70] N. Holzer, K. F. Braun, S. Ehnert, J. T. Egana, T. L. Schenck, A. Buchholz, et al., "Green Tea Protects Human Osteoblasts from Cigarette Smoke-Induced Injury: Possible Clinical Application," Langenbecks Archives of Surgery, Vol. 397, No. 3, 2012, pp. 467-474. doi:10.1007/s00423-011-0882-8

[71] C. L. Shen, J. K. Yeh, J. J. Cao, O. L. Tatum, et al., "Green Tea Polyphenols Mitigate Bone Loss of Female Rats in a Chronic Inflammation-Induced Bone Loss Model,” Journal of Nutritional Biochemistry, Vol. 21, No. 10, 2010, pp. 968-974. doi:10.1016/j.jnutbio.2009.08.002 